\title{
Ensuring the amphibious capabilities of the amphibious vehicle based on the hydrodynamic buoyancy principle
}

\author{
Sergei Abdulov ${ }^{1}$, Ilya Trusevich ${ }^{2,}$, and Alexander Volkov ${ }^{1,2}$ \\ ${ }^{1}$ Kurgan State University, 640020, Kurgan, Russia \\ ${ }^{2}$ IES UB RAS, Department of Transportation Vehicles Mechanics, 620049, Ekaterinburg, Russia
}

\begin{abstract}
This work substantiates the technical solutions for ensuring high water speed of the future amphibious vehicle by the implementation of the movement regime based on the principle of hydrodynamic buoyancy. The conclusions obtained in the course of the search work are proved with the help of computational hydrodynamics modeling.
\end{abstract}

Cargo transportation and manufacturing support on the vast but underdeveloped territories of Western and Eastern Siberia, the Arctic, the Far East and Baikal region are serious state problems. Many official documents address the issues of importance of developing transport infrastructure within these territories. $[1,2,3]$. Specific features of these regions are underpopulation, poor development of railroads and road traffic routes. However, in that severe environment it is necessary to carry out transportation of multiple and different cargoes at long distances. In addition there are often no roads or their bad conditions with plethora of water bodies on the way.

Among all-terrain vehicles the amphibious vehicles hold a special place.

Amphibious vehicles are special vehicles that able to travel by land and by water alike. At that, preparation for movement on water is not required or takes very short time interval as result of design features of those vehicles.

Combination of good cross-country ability and possibility of continuous operation on water places amphibious vehicle in special group that can be used in various industries.

The first amphibious vehicle was built in the late of the 18th century. But the real development of amphibious vehicles began in the 1920s. Most often, these vehicles had been developing at the request of the military.

In addition to the military amphibious vehicles there are civilian ones that used in variety of areas. Mostly these are transport vehicles which needed for cargo transportation and providing of the workflows in water environments and rough terrain. The civilian amphibious vehicles are often based on the military ones.

In numerous domestic and foreign technical studies the various design and development aspects of common and special cars, and all-terrain vehicles are quite fully described, but it is not true for amphibious vehicles.

\footnotetext{
* Corresponding author: mrtrilal@gmail.com
} 
The issues of amphibious vehicle design and ensuring the required amphibious characteristics are not sufficiently covered in the technical literature. Publications are very limited and mostly deal with separate issues without consideration of designing as a whole.

Despite the shortage of specialised materials about amphibious vehicles, many of topical issues are discussed in the shipbuilding literature, for example, edited by $\mathrm{Y}$. Voytkunski $[4,5,6]$. Major efforts in amphibious vehicles domain were done by A. Stepanov [7], who in addition to his book wrote many separate works, handbooks, tutorials, and publications. Water propulsion units were examined in detail by A. Rusetsky [8], A. Papir [9], S. Kulikov [10].

In foreign technical literature it is worth noting the joint works of engineers Ehrlich I.R., Kamm I.O., Worden G. [11,12]. Among the numerous sources relating water propulsion unit one can note scientific team - Ehrlich I.R., Sloss D., Hanamoto B., Nutall C.J. [13], as well as fundamental work of Carlton J. [14].

Throughout the history of design and development of amphibious vehicles the efforts were pursued to increase speed of movement on the water. It was assumed that increase of engine power, improvements of water propulsion, using of new materials would allow significantly reducing time to negotiating water obstacles.

The main obstacle for the speed increasing is the hull of amphibious vehicles has illstreamlined shape. Significant contribution to total resistance makes the running gear of the vehicle.

The purpose of this work is the search of technical solutions ensuring high speed of the amphibious vehicle on the water, seaworthiness up to Sea State 3-4.

The drag to vehicle movement on the water in amphibious regime $\mathrm{R}, \mathrm{H}$, in first approximation is described by the dependence:

$$
R=k \rho_{B} v^{2} S_{M}
$$

where $\quad k$-dimensionless coefficient characterizing the shape of hull outlines;

$v$ - vehicle speed, $\mathrm{m} / \mathrm{s}$;

$S_{M}$ - cross-section area of immersed part of the vehicle, $\mathrm{m}^{2}$.

As it follows from equitation (1), the drag can be diminished only by improving the shape of hull outlines, $k$ parameter, and by reducing $S_{M}$ cross-section area. The drag increasing depends on movement speed in second power, respectively power increasing in third power.

Ideal for amphibious regime is the hull in the shape of long streamlined boat with maximum enclosed land propulsion unit. One demonstration of such approach is upgrade of tracked vehicles of China- Figure 1.

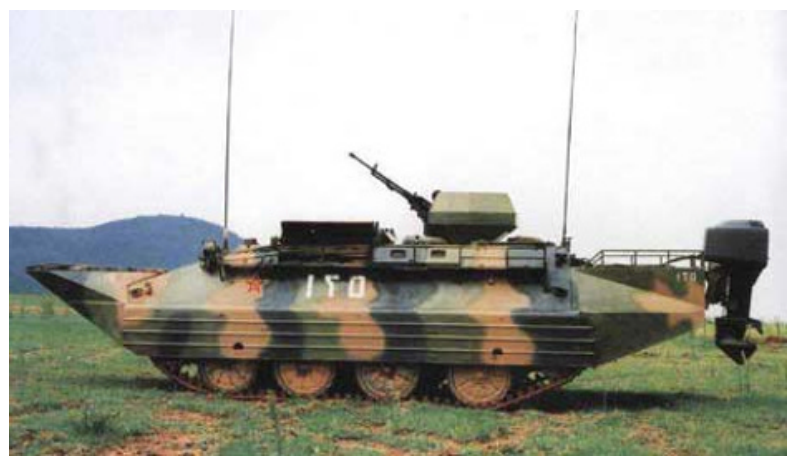

Fig. 1. Chinese WZ-501 amphibious IFV 
Fore and aft floats installed on production vehicle increase vehicle length and reduce wave drag. Running gear is covered with side skirts resulting in reduction of eddy formation. For efficient operation of aft-mounted outboard motor the sufficient water supply is provided. Note that the efficiency of propeller is 2-3 times higher that of water jets, especially tracks. It can be expected that the package of measures allows to ensure vehicle steady movement in the amphibious regime at speed $12 \mathrm{~km} / \mathrm{h}$. At the same time the power of outboard motor is several times less than the power of vehicle engine.

The disadvantage of this approach is long bow and stern overhang - limited gradeability on land, also when entering the water from ship ramp the damage to protruding parts is possible. Further increase of speed in amphibious regime prevents the rapid increasing of the movement drag, respectively the required power increases faster.

From equitation (1) it is obvious that to reduce the drag significantly we need to raise the hull and the running gear above the water level. One way is to create excess pressure in the air cushion. [15 - 18]. This method has been studied in detail, it is used now on some all-terrain vehicles, but given high energy expenditure, the need for all-terrain transport vehicle to negotiate obstacles such as ups and downs, to travel off roads and several of other factors the movement on air cushion is not considered in this work.

Another way of takeoff the hull from the water is the hydrofoils $[15,19]$.

The main advantage of hydrofoil propulsion compared to gliding is more efficiency for the same lifting force, hydrofoils have less drag and, as result, the power consumption is less. Alongside with that the wave impacts on the hull decrease - reduced impact loads. The position of center of gravity is easier to coordinate with hydrodynamic forces on the wings.

The disadvantages of the hydrofoils are greater drag of protruding parts in amphibious and transitional regimes. For amphibious vehicles it is necessary to provide for the system of hydrofoils raising/lowering, to solve problem of the carrying hydrofoils on the land. Tests also demonstrated the need of control system of attack angles of the hydrofoils for correct hydrofoil regime in case of change of the vehicle loading.

Returning to amphibious regime it should be noted that main force that supports vehicle on the water is hydrostatic uplift. With speed increasing the hydrodynamic forces begin to act on the vehicle that can be significantly affects its immersion in the water. Depending on the ratio of hydrostatic and hydrodynamic buoyancy forces there are three speed regimes of movement: floatation, transitional regime and gliding.

The boundary between movement regimes on the water is usually estimated by the displacement-Froude number:

$$
F r_{D}=\frac{v}{\sqrt{g \sqrt[3]{D}}}
$$

where $\quad v$ - vehicle speed, $\mathrm{m} / \mathrm{s}$;

$D$ - vehicle displacement, $\mathrm{m}^{3}$.

The following boundaries are established between regimes:

- floatation

- transitional regime

- gliding

$$
\begin{aligned}
& F r_{D}<1,0 \\
& 1,0<F r_{D}<3,0 \\
& F r_{D}>3
\end{aligned}
$$

Considering that the vehicle weight $M$, t, is numerically equal to the vehicle displacement $D, \mathrm{~m}^{3}$, we will plot the following graph - Figure 2 .

One can see from Fig. 2 that the beginning of the transitional regime for $15-40 \mathrm{t}$ vehicles corresponds to about $20 \mathrm{~km} / \mathrm{h}$, and transition to pure gliding is possible only at 55$60 \mathrm{~km} / \mathrm{h}$. For example, the EFV with weight $35 \mathrm{t}$ at maximum speed of $46 \mathrm{~km} / \mathrm{h}$ moves in transitional regime. 
In transitional regime, if you do not take follow-up measures, the aft different emerges significantly, the aft displacement increases, the wave drag increases sharply. To reduce drag it is necessary to change the hull shape and/or install additional supporting elements that contributes to vehicle exiting from the water. All of this was implemented on the EFV - Figure 3.

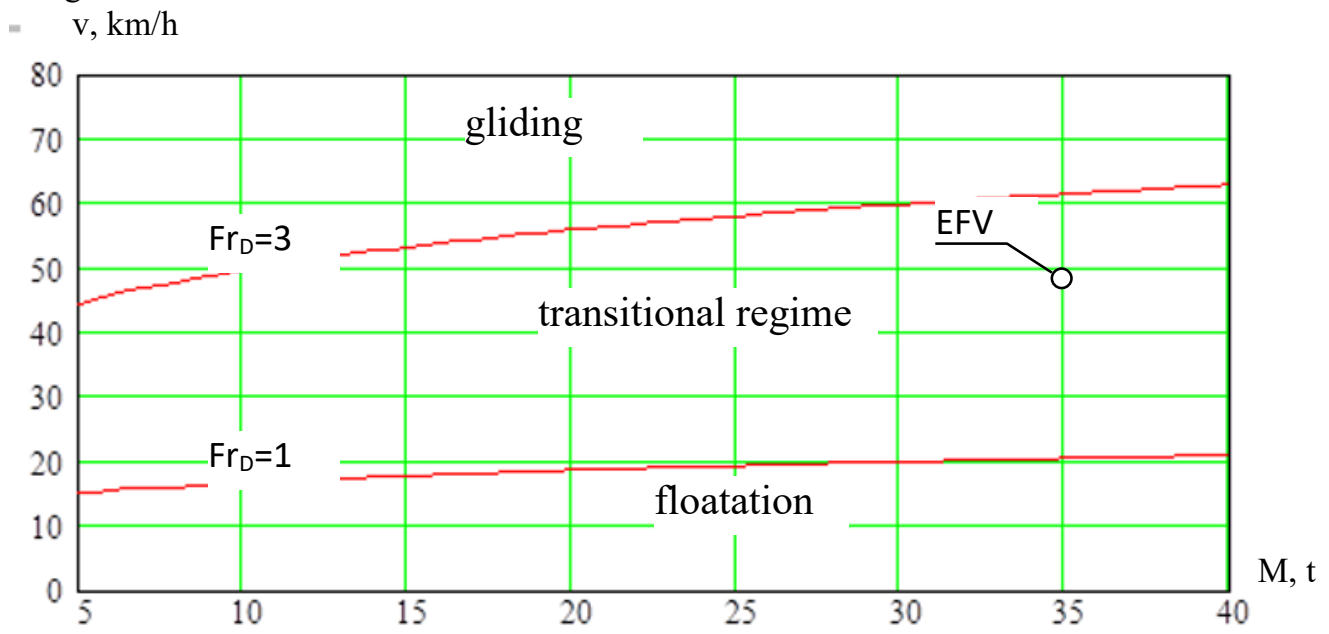

Fig. 2. Boundaries between movement regimes

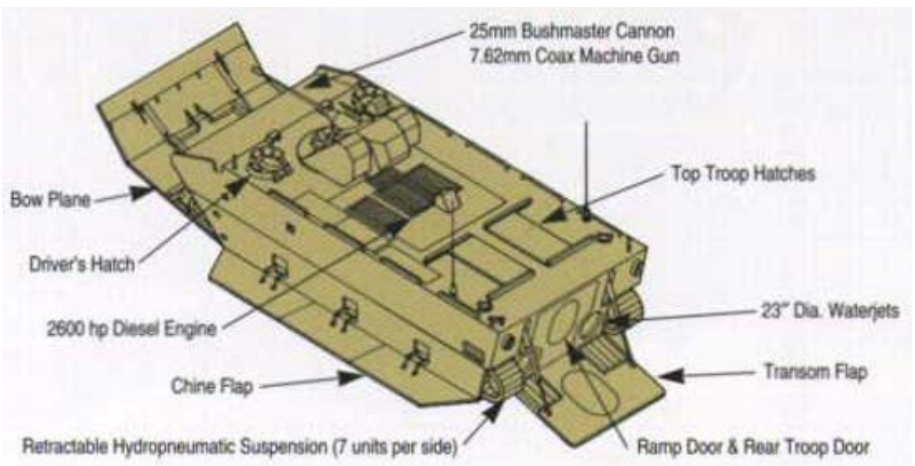

Fig. 3. Scheme of transformation of the EFV for high-speed movement regime

With sufficient engine power and propulsion thrust it is possible transition to gliding [20]. In gliding regime the vehicle weight is almost completely balanced by hydrodynamic forces, the vehicle hull comes out of water, the drag force increasing slows down.

The disadvantage of the movement in gliding regime of monohull vehicle is sensitivity to center-of-gravity position. For each value of speed there is own optimal position of center of gravity over dynamic forces center. Any displacement of the center of gravity from optimal position prevents transition to gliding regime. In case of unfavorable position of the center of gravity the transition to gliding regime is not possible. In part the problem can be fixed by additional elements such as transom plates, folding afterplate, control of thrust vector of the propulsion.

Also, when travelling on the high waves the gliding hull withstands heavy shocks, in particular on the flat elements. In case of the EFV these shocks are on folding bow plate, side plates, hull. Apart from the necessity of ensuring structural strength, hence weight 
increase, these shocks affect the performance of the vehicle systems and mechanisms, crew health.

The above technical solutions for increasing speed on the water are implemented in monohull vehicles. Meanwhile, highest cross-country performance is implemented in articulated vehicles. Models of two-sectional vehicles are successfully operated in different countries, Sweden, Singapore, Russia, Canada, etc.

Domestic two-section tracked vehicles even without special water propulsion unit have the best characteristics to exit from water on raw bank including on the ice.

There is no experience of the development of high-speed amphibious vehicles on the basis of two-section ones. Considering that the increase in the ratio of the length of vehicle to its width leads to decrease in wave drag, it is proposed to consider the possibility of implementing high-speed movement on the water on the basis of two-section amphibious vehicle. In addition to all the considered technical solutions for increase the speed on the water, the possibility of using rotary-coupling unit (RCU) is added for effective control of hydrodynamic forces on the hulls and special supporting elements.

To study the amphibious vehicle movement on the water the STAR-CCM+ [21, 22, 23] technological package for engineering simulation based on the computational hydraulic gas dynamics was used. The simulation tool covers a variety of engineering disciplines, which provides accurate interdisciplinary calculations in single integrated user interface. This software package allows of performing full-scale simulation under actual operating conditions and evaluating designer's ideas and solutions.

Similar calculation in the STAR-CCM+ was performed by V. Filatov [24], there are examples of similar simulations in the other software packages [25].

The main hydrodynamic calculations were performed for the two-section vehicle - Fig. 4-6. Concurrently, it was demonstrated the need to control articulation angles in different regimes of movement. In the transitional regime it is necessary to articulate sections so that hydrodynamic forces ensure the exit of the first section from the water. As the speed increases it is necessary to reduce the drag increasing. At maximum speed the articulation angle is determined from the criterion of maximum efficiency of the hydrodynamic interaction of the sections.

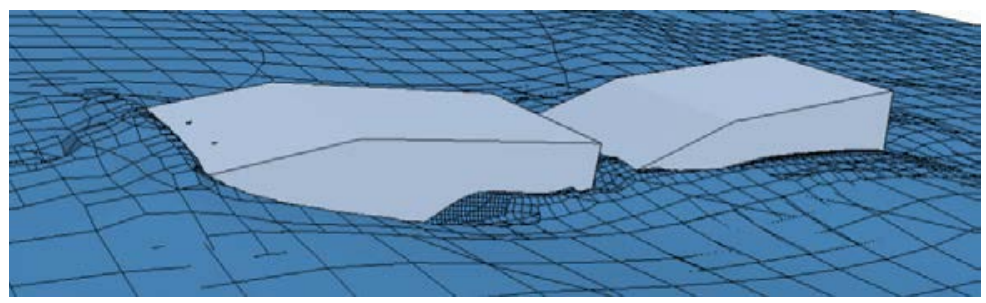

Fig. 4. Movement speed $5 \mathrm{~m} / \mathrm{s}$, articulation angle of sections $10^{\circ}$

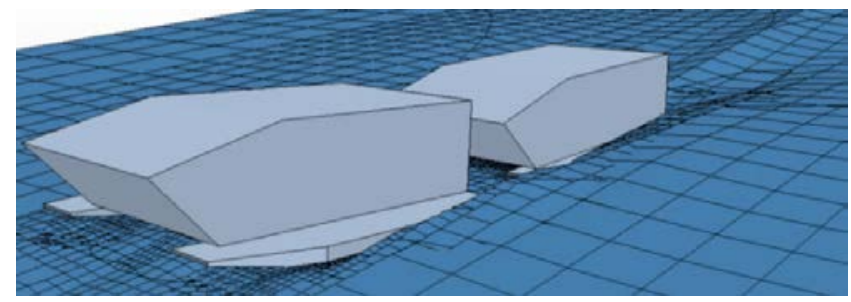

Fig. 5. Movement speed $10 \mathrm{~m} / \mathrm{s}$, articulation angle of sections $5^{\circ}$ 


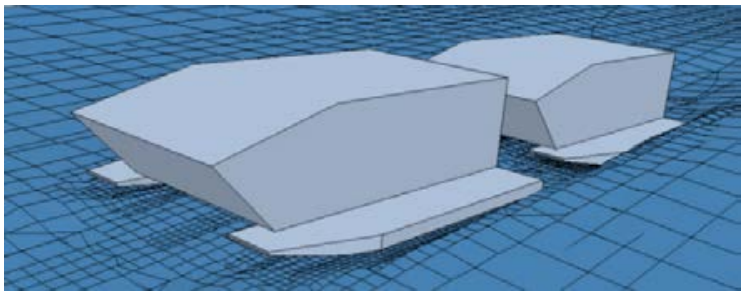

Fig. 6. Movement speed $15 \mathrm{~m} / \mathrm{s}$, articulation angle of sections $0^{\circ}$

To evaluate the effectiveness of different options of installation of additional elements and the variations of articulation angles between sections the simulation modeling was performed. The results are shown in Fig. 7.

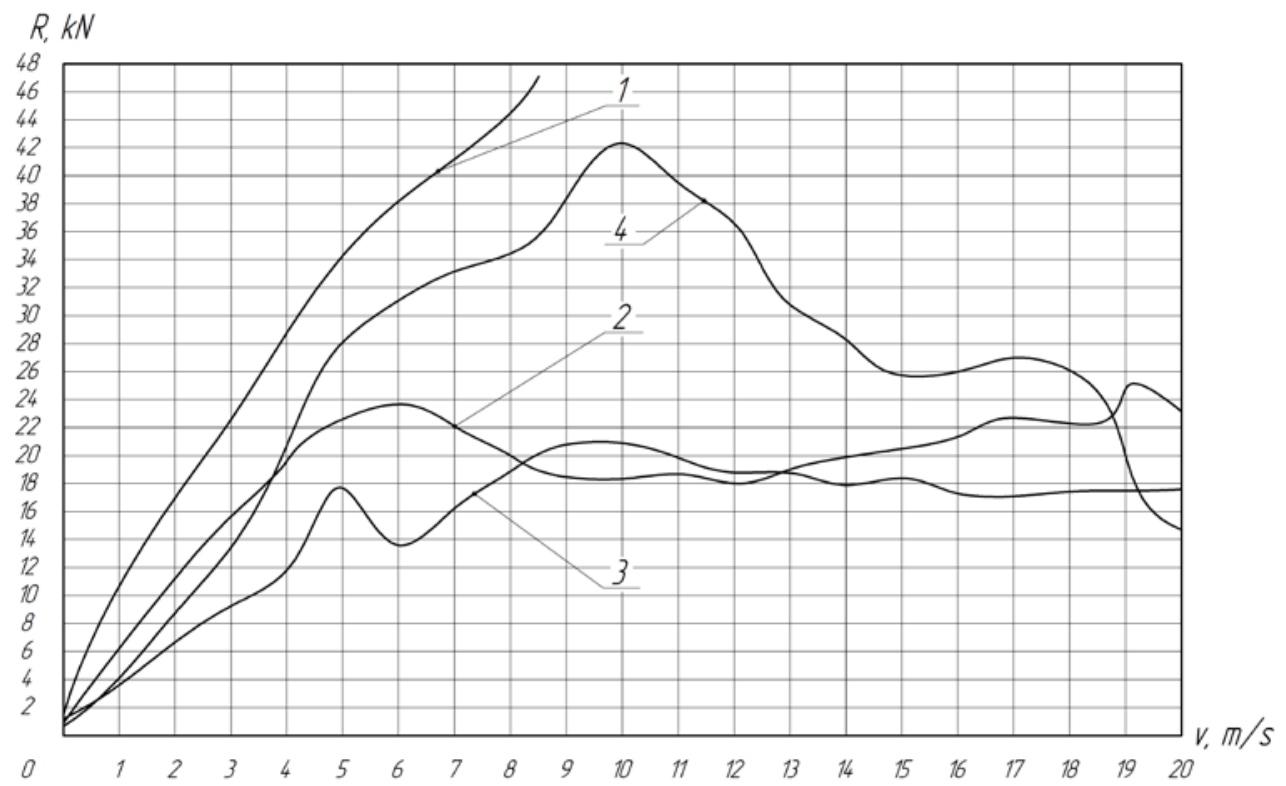

Fig. 7. Water drag force for different options of installation of additional elements:

1 - without additional elements; 2 - with hydroskis; 3 - hydrofoils + RCU operation; 4 - hydroskis and bow hydrofoil.

Based on the analysis of simulation results it was found that:

The amphibious vehicle can not transit to regime with the hydrodynamic buoyancy principle without installation of additional elements when propulsive force is in the range 6 to $48 \mathrm{kN}$;

«Skis» installation, without RCU operation, allows the first section to exit the water and to start pulling the second one that at the same time is submerged partially. As a result, on the graph we get another drag «hump» superior to the first one;

Due to «skis» installation and RCU operation we manage to implement the most effective high-speed movement regime on the water;

The installation of the bow hydrofoil without the control system of the attack angles increases greatly the overall drag. 


\section{Conclusions}

1. Quantum leap in the speed from $10-12 \mathrm{~km} / \mathrm{h}$ to $40-50 \mathrm{~km} / \mathrm{h}$ possible only by transition from amphibious regime to regime with hydrodynamic buoyancy principle - the bulk of the hull is buoyed above the water. At the moment, the most studied and implemented are: gliding regime and the movement on the hydrofoils - for this the vehicle requires additional supporting elements.

2. When movement in the hydrodynamic buoyancy regime the ensuring a high speed on the water is possible when power-to-weight ratio at least $80 \mathrm{hp} / \mathrm{t}$ and high propulsive coefficient of the water propulsion unit (from 0.3).

3 . The increasing speed on the water is not possible by the increasing engine power only. For selected regime it is necessary to modify the hull shape, to install additional elements.

4. For efficient use of supporting elements the systems are required for unfolding and retracting them in the water, as well as for control of supporting elements in different regimes of movement.

5. Considering the dependence the drag forces and required power on the dimensions and weight of the vehicle it is necessary always to seek to reduce the gross vehicle weight and the weight contribution of additional elements.

\section{References}

1. Development strategy of the Arctic of the Russian Federation and ensuring national security for the period up to 2020 .

2. The basis of the state policy of the Russian Federation in the Arctic for the period up to 2020 and beyond.

3. Strategy of social and economic development of the Far East and the Baikal region for the period up to 2025 .

4. Y. Voytkunski, Handbook of ship theory: in 3 volumes. Volume 1: Hydromechanics. Drag to ship movement. Ship power plants. (1985)

5. Y. Voytkunski, Handbook of ship theory: in 3 volumes. Volume 2: Ship statics. Ship rolling. (1985)

6. Y. Voytkunski, Handbook of ship theory: in 3 volumes. Volume 3: Course-keeping qualities of the displacement-type ships. Ship hydrodynamics with hydrodynamics support principles. (1985)

7. A. Stepanov, The engineering of the amphibious vehicles. (2007)

8. A. Rusetsky, Power plants of ships with dynamic uplift principles: Tutorial. (1979)

9. A. Papir, Water-jet propulsion units of the small crafts. (1970)

10. S. Kulikov, M. Hramkin, Water propulsion units (theory and calculations). 3-rd ed., reworked. (1979)

11. I.R. Ehrlich, I.O. Kamm, G. Worden, Journal of Terramechanics, Water performance of amphibious vehicles. Part I - Drag and water speeds, vol 7 N 2, pp. 61-102, (1970)

12. I.R. Ehrlich, I.O. Kamm, G. Worden, Journal of Terramechanics, Water performance of amphibious vehicles. Part II - Propulsion and maneuverability, vol 7 N 3-4, pp. 6999, (1970)

13. I.R. Ehrlich, D. Sloss, B. Hanamoto, C.J. Nutall, Journal of Terramechanics, The wheel pump propulsion system for floating vehicles, vol. $8 \mathrm{~N} 4$, pp. 43-52, (1972)

14. J. Carlton, Marine Propellers and Propulsion (Second Edition). (2007) 
15. G. Zlobin, S. Smigelsky, Hydrofoil ships and air-cushion ships. (1979)

16. S. Adasinsky, Air-cushion transport vehicles. (1964)

17. G. Demeshko. Ship design. Air-cushion amphibious vessels: Textbook. 2 vol. Vol. 1. (1992)

18. G. Demeshko. Ship design. Air-cushion amphibious vessels: Textbook. 2 vol. Vol. 2. (1992)

19. P. Ziganchenko, B. Kuzovenkov, I. Tarasov, Hydrofoil ships (designing and strength), (1981)

20. M. Timofeev. Hydrodynamics of the gliding amphibious vehicles: thesis, (2003)

21. DFBI: Boat in Head Waves

22. DFBI: Lifeboat with Overset Mesh

23. Marine Resistance Prediction: KCS Hull with a Rudder

24. V. Filatov, Herald of civil engineers, The hydrodynamic studies of the future amphibious vehicle of small class, 2(61), pp. 219-223, (2017)

25. İ. Kurtoğlu, Hydrodynamic Drag Force Predictions for Amphibious Military Vehicles, (2017) 